\title{
Varte
}

\section{- Entrevista a Manuel Barbadillo}

\author{
Inmaculada España Cordero
}

Estudio del pintor, Torremolinos, Málaga, 16 de Julio del $2002^{1}$. Entrevistadora y transcripción: Inmaculada España Cordero.

¿Por qué eligió Málaga, en concreto Torremolinos, en la década de los sesenta como ciudad para vivir y en qué año se instaló definitivamente? Personalmente no creo que fuese por razones artísticas ya que otras ciudades como Madrid o Barcelona le ofrecian posibilidades más favorables para el desarrollo de su obra artistica. Por otra parte, su estancia anterior en países y ciudades como Marruecos o Nueva York entre otras circunstancias encerraba un componente artístico.

- Si, bueno, yo estuve en Málaga por primera vez, antes de los años sesenta, en los años cincuenta, hacia el 53 , estuve aquí unos días pues iba de paso hacia Melilla para hacer el servicio militar como oficial de la milicia universitaria y me fui muy contento tras estos días. Ya entonces Málaga me gustó mucho, tanto fue así que cuando terminé el servicio militar no volví a Sevilla, ciudad de la que soy, y regresé a Málaga, en concreto a Torremolinos. Torremolinos entonces no tenía nada que ver con lo que es Torremolinos ahora, era un pueblecito muy pequeño, con algunos turistas, yo diría más bien turistas entre comillas. Eran más bien extranjeros que estaban aquí, había muchos pintores, escritores, músicos, en general eran artistas que estaban aquí, o bien trabajando en su obra o bien tomándose unas vacaciones. A mí me gustó mucho ese ambiente y se quedó en mi mente la idea de Torremolínos.

Por lo que me cuenta era un ambiente muy bohemio, no era a lo mejor el ambiente de galerías como pudiese existir en Madrid o Barcelona ¿no?

- Efectivamente, galerías no había ninguna, ni salas, tampoco el ayuntamiento tenía una sala o sitio donde se pudiese exponer. Pero aquí, en Torremolinos, aparte del clima y la belleza del paisaje, había un ambiente muy interesante de gente creativa, de todas maneras Málaga también me gustó, pero, en fin, preferi Torremolinos. Esto fue al pasar hacia Melilla en el año 53. Al acabar el servicio militar estuve un tiempo, en concreto varios años, por diversos sitios de Marruecos, tras

ESPAÑA CORDERO, Inmaculada: "Entrevista a Manuel Barbadillo", en Boletín de Arte, n² 24, Universidad de Málaga, 2003, págs. 603-624. 


Q: VIstraculada España Cordero

esto regresé a la península, pero no a Sevilla sino a Torremolinos. Aquí en Torremolinos conocí a la que es hoy mi mujer, ella estaba pasando unas vacaciones y tenía que volver a Nueva York, a la universidad pues estaba estudiando, entonces ya nació en mí la idea de vísitar Nueva York, en parte por verla a ella, y en parte porque me empezó a interesar mucho el movimiento de pintura que se estaba dando en América por aquellos años, el Expresionismo Abstracto. Roma y París, ciudades por las que pasé y por las que pasaban los artistas para ponerse al día ya no me interesaban, en cambio el movimiento americano me interesaba mucho. Cuando inicié la relación con la que era por entonces mi novia tomé la decisión de ir a América, y cuando tuve dinero para hacerlo tras haber pintado unos murales que me salieron marché para Nueva York, allí me casé con ella, vivimos varios años y allí nació uno de mis hijos. Luego decidimos venir a España a pasar unas vacaciones de unos seis $u$ ocho meses. Vinimos, estas vacaciones se fueron prolongando y todavia hoy estamos aquí.

¿Fue decisivo el papel de Marruecos y su arte no figurativo en su obra, o mejor dicho, en el paso definitivo de su obra de figurativa a abstracta?

- Yo creo que sí, porque ya en los últimos meses de estancia en Marruecos empecé a hacer obras abstractas, lo que pasa es que eran pasos titubeantes, yo seguía haciendo todavia una pintura figurativa, no era figurativa estrictamente, tampoco era realista, se veían figuras, estas fíguras eran más o menos expresivas, más o menos deshechas, eran medio figurativas medio abstractas, pero también empecé a hacer unos cuadros completamente abstractos, esos fueron mis últimos tiempos en Marruecos en el año 57. Ese año, si no recuerdo mal, hice una exposición en Tetuán, exposición que luego lleve a Tánger en la que había algunos cuadros completamente abstractos.

¿Y la influencia de Marruecos en su posterior obra modular?Por ejemplo, Rosario Camacho y Maria Dolores Aguilar Garcia escribieron un articulo sobre su obra modular, en este artículo veían puntos de contacto entre su obra modular y el arte geométrico islámico, ya que ambos utilizáis figuras geométricas y curvilineas, ambos os basáis en la repetición de módulos y en el ritmo. ¿Esto es algo que se ha querido ver o realmente es así? ¿Qué me dice al respecto?

- Aunque la forma geométrica aparece después, años después de haber venido de Marruecos, yo creo que fue consecuencia de las experiencias marroquíes. A mí el impacto que me produjo Marruecos fue muy fuerte, no solamente la forma geométrica de la decoración marroqui y de la arquitectura marroquí, también la música marroquí,

\footnotetext{
${ }^{1}$ Ante el valor de documento que la entrevista que mantuvimos con Manuel Barbadillo posee debemos decir que hemos intentado reproducirla lo más fielmente posible a como fue, es decir, hemos intentado eliminar lo menos posible, por ello algunos fragmentos parecen repetitivos.
} 
del país en sí. En Marruecos me ocurrió algo que ya ocurrió anteriormente a otros pintores como Matisse o a Paul Klee, y es que Marruecos fue para mí una experiencia impactante, me encontré con una civilización completamente distinta a la nuestra, a pesar de que España fuese invadida y colonizada por los árabes.

Perdone que le corte, pero sobre todo nosotros al vivir al Sur quizás podamos estar más familiarizados con este tipo de arte que otras personas.

- Eso lo he pensado yo también a veces. En Sevilla hay sitios, por ejemplo el Alcázar, como supongo que la Alcazaba aquí en Málaga, que yo no la he visto por dentro nunca, pero donde hay muchos elementos geométricos en los mosaicos, en el pavimento, o sea que podría estar ya latente en mi interior por haber nacido en Sevilla y haberme criado alli esa afinidad por la forma geométrica de la arquitectura y de la decoración marroquí o árabe. Pero en Marruecos me encontré todo eso en su "salsa", además rodeado de su música, de su baile, de la fiesta marroquí, de la vestimenta, de los zocos, en fin, mi experiencia en Marruecos fue impactante, como te dije antes, pero no apareció en mi pintura hasta después de haber dejado Marruecos. Esto es algo que me ocurre a mí, que cuando vivo algo que luego afecta marcadamente a mi pintura no me ocurre al instante, sino que parece que lo capto primero por el subconsciente, lo dejo elaborar durante algún tiempo y aparece más tarde. Realmente hasta mis últimos tiempos en América no aparece la pintura geométrica en mi obra. Yo creo que sí, que tienen razón Rosario Camacho y María Dolores Aguilar García.

Dentro ya de su obra abstracto informalista se ha hablado de la influencia de Tápies, siempre se ha hablado de influencia, pero ¿realmente le llegó a conocer?

- Personalmente no le conocí, las primeras obras suyas que conocí fue a través de reproducciones en las revistas de arte y me interesó mucho, me llamó mucho la atención porque era algo totalmente diferente, sin embargo no empezó a aparecer su influencia en mi pintura hasta después, estando ya en América.

¿Y la influencia de Estados Unidos y Pollock? Porque vamos a ver, Pollock hace ante todo un informalismo gestual, mientras su pintura informalista se va a caracterizar por una pintura de materia ya que su paso por el informalismo de acción es muy efímero, y precisamente Pollock no se va a caracterizar por la pintura de materia, aunque también hiciese cuadros de pintura de materia, él va a dominar más que nada el gesto, entonces dígame ¿qué influencia hay de Pollock en su obra? ¿le conoció personalmente? ¿Dónde le vio por primera vez?

- Es cierto que mi etapa por el informalismo de acción fue muy breve, pinté sólo tres o cuatro cuadros. Por lo que respecta a Pollock éste ya había muerto cuando llegué a Estados Unidos, pero allí pude ver su obra en persona. Mi propia obra no tenía afinidad con la obra de Pollock, sin embargo, a mi su obra me producia una 
sensación de estar ante algo que es bueno, que vale, no sé si es porque Pollock terminó por completo con la pintura del natural, ya que a la pintura abstracta que existía antes de Pollock, aunque fuese abstracta, de alguna manera u otra todavía le quedaban residuos de la naturaleza. A esto se une que Pollock reduce por completo el cuadro a una unidad, sin un centro, no hay un foco de interés en el cuadro, hace de toda la obra un aformalismo, él le quita por completo la forma al cuadro. Lo que él quiere representar, y lo que representan sus obras, es la energía creativa, la forma desaparece por completo; eso no habia ocurrido en otros pintores antes que él, incluso en pintores abstractos, porque de alguna manera u otra había forma, aunque no fuese naturalista, realista o figurativa, pero hay forma, formas que están en una relación natural, es decir, aunque sean formas que no representan un objeto, sin embargo, todavía la atmósfera del cuadro sigue en algo a la naturaleza, bien por los colores, bien por la relación de las formas. En Pollock no, porque Pollock tiraba la pintura, buscaba el automatismo, para dejar expresar así su energía interna. Esto es lo que me interesó de él, porque para empezar a hacer la obra geométrica que yo hice después tenía que barrer toda la historia de la pintura, y eso ya lo había hecho Pollock, Pollock no hizo pintura geométrica pero prepara el terreno para poder hacer la pintura modular que yo hice después.

¿Y la influencia de la Escuela de Paris? Porque de algún trabajo se deduce más o menos que ya antes de ir a Estados Unidos usted pudo conocer la pintura de materia a través de la Escuela de Paris.

- Yo no conocí muy bien la Escuela de París, había visto alguna obra, sobre todo de Fautrier, pero tal vez tuviese alguna influencia sobre mí de la que yo no soy muy consciente. Ya en mis primeros cuadros abstractos de los años 56 o 58 la materia jugaba un papel, aunque no era un papel único y predominante como ocurre en Fautrier, y después en Tápies; la materia era un elemento más, la textura del cuadro era un elemento que yo valoraba como la forma o el color o la composición, o sea que era un elemento importante, pero no llegué a trabajar exclusivamente con la materia como sí hicieron Fautrier o Tápies. O sea que la Escuela de París alguna influencia, algún impacto, creo que sí que tuvo sobre mí, pero muy poco, yo creo que de la Escuela de París pasé muy rápidamente a interesarme en la obra de Tápies, y luego de la influencia de Tápies y la pintura de materia pasé a lo geométrico.

En mi trabajo hablo constantemente de adecuación, veo que en su obra se da una adecuación, primero a un panorama nacional con esa formación academicista figurativa porque no le queda más remedio, ya que es lo que existe realmente en España cuando inicia su formación artística, más tarde se adapta a un panorama internacional con el informalismo, y más tarde al Neoconstructivismo. ¿Usted ve tal adecuación?

- Yo creo que es una coincidencia, porque mi camino de la pintura de materia a la pintura geométrica se fue produciendo sin relación a la pintura geométrica que ya 
se estaba gestando en el resto del mundo. Yo empecé haciendo bajo la influencia de Tápies unos cuadros que estaban texturados, cubiertos de materia texturada de extremo a extremo, luego comencé a dividir esas formas texturadas, cada vez en porciones más pequeñas y cada vez más ordenadas en relación al eje vertical y al eje horizontal. O sea que yo pasé de la pintura de materia a la pintura geométrica en un proceso de división y de conformación. Yo dividia la materia en trozos más pequeños y los perfiles de estos trozos pequeños cada vez se iban uniformizando más y geometrizando más. Cuando yo estaba inmerso en este proceso todavía no me había empezado a interesar la pintura geométrica extranjera, realmente no la había, sí existian los precedentes históricos, pero el movimiento geométrico de las nuevas vanguardias, las raíces del minimalismo y todo eso, aún no había salido a la luz, se estaba haciendo en los estudios de los artistas pero todavía no se hablaba de ello ni se veía. Yo tomé un camino propio sin saber que buscaba la pintura geométrica, eso es asi que cuando me salió el primer cuadro con forma geométrica y en blanco y negro, ya sin colores, para mi fue una sorpresa muy grande, me hacía pensar en la obra de Arp, en la obra de Delaunay, o sea, en los precedentes de arte geométrico que había habido en la primera mitad de siglo. Todo esto me sorprendió mucho y yo me preguntaba ¿Pero qué he hecho? ¿Por qué me sale a mí esto ahora? Solamente me sentí reafirmado en mi posición cuando empecé a tener noticias de que se estaba haciendo arte geométrico nuevo en otros países.

Entonces mejor que hablar de adecuación habria que hablar de coincidencia, sobre todo en esta última parte ¿no?

- Sí. Coincidencia en los resultados no en los procesos, porque hay pintores geométricos de fuera de España que empezaron a hacer arte geométrico a finales de los cincuenta o principio de los sesenta que lo hicieron por un proceso de influencia del arte geométrico anterior, yo en cambio llegué a lo geométrico sin saber que iba buscando lo geométrico.

¿Qué entiende usted por obra de arte autónoma? aspecto, por otra parte, tan discutido a lo largo del siglo $X X$.

- A veces lo he leído en relación con mi pintura; Enrique Castaños Alés hablaba de ello en la introducción a un catálogo de una exposición mia antológica que tuve en Málaga. Él hablaba de obra de arte autónoma, y yo no se muy bien qué podría significar eso de obra de arte autónoma. Si por obra de arte autónoma se refiere a que la obra de arte no tiene relación alguna con el resto de las manifestaciones culturales o no culturales, o sea, es una obra centrada en sí misma, que no tiene nada que ver con todo lo demás, entonces mi obra no es autónoma, porque mi obra creo que sí tiene una relación muy profunda con la naturaleza, no a través de la representación de formas visuales o naturales, sino simplemente partiendo del hecho de considerar a mi obra modular como la naturaleza que también es modular, la naturaleza opera en todo con pocos elementos y por combinaciones se hace todo. 
Bajo mi punto de vista de la relación entre el arte y la naturaleza mi obra no es autónoma, mi obra tiene una relación muy estrecha con la naturaleza. En relación con otras artes, decirte que la música es básicamente modular también, la música parte de unos módulos, que son las notas musicales, y se crea por combinación de estos módulos.

\section{¿Y con la arquitectura?}

- La arquitectura ya tiene menos relación con mi obra, porque son pocos arquitectos los que han llegado a crear una arquitectura modular, pero también ha habido arquitectos modulares, en España por ejemplo existió Rafael La Hoz que era completamente modular, Le Corbusier es muy modular. Lo que pasa en la arquitectura es que está muy determinada por cuestiones que no son puramente estéticas, es decir, la arquitectura necesariamente tiene que ser funcional, entonces no puede operar con absoluta libertad formal, por ello el modularismo en arquitectura ha sido mucho menor que en el resto de las otras artes, e incluso de la química y la naturaleza. Pero ha habido arquitectos modulares, en Le Corbusier la modularidad es muy evidente, en España Rafael La Hoz es un arquitecto muy importante, a pesar de estar ahora oscurecido su nombre por las modas estéticas.

¿Qué entiende usted por investigación? palabra ésta que va tan unida a su obra.

- Bueno, éste es un punto muy difícil de contestar. Yo considero que mi obra procede de lo irracional y del inconsciente y no es producto de la meditación, entonces, ¿cómo pienso al mismo tiempo que la obra de arte es producto de la investigación? Bueno, la razón es que yo creo que el subconsciente también razona, aunque de forma diferente a la mente. El subconsciente debe tener un proceso de procesar, valga la redundancia, la información que recibe que debe tener un elemento de racionalidad grande, lo que pasa que como se adelanta a la mente en ese proceso, cuando se manifiesta, se manifiesta mediante intuiciones, nosotros lo llamamos intuiciones porque no podemos afirmar que se trate de un proceso racional. Pero sí puede ser también un proceso racional, aunque un proceso racional que maneja información que a la mente todavia no ha llegado o no posee, entonces cuando hace sus manifestaciones no las podemos encajar en un proceso evolutivo, entonces lo llamamos intuiciones, que es como decir adivinaciones, corazonadas o llamaradas. Yo creo que el subconsciente también utiliza la razón, aunque creo que a la sombra claramente.

Hablemos ahora de su obra modular, expliqueme conceptos como el ritmo, el espacio y el movimiento.

- El ritmo en mi obra es fundamental y es muy literal, es decir, musicalmente podemos decir que hay un ritmo de dos por tres, de dos por uno, es decir, hay una relación matemática que está muy clara en la música. En los ritmos musicales una 
obra musical se puede descomponer hasta llegar a sus elementos básicos que son las notas musicales y entonces encontrar las relaciones matemáticas que existen entre unas notas y otras. Yo utilizo la palabra ritmo en ese sentido, como mi obra parte de unos elementos básicos que son muy claros, o sea que se puede aislar una de estas formas básicas del resto del cuadro; esto no se puede hacer cuando las formas se funden unas con otras, aqui no se puede hablar de ritmo porque no se pueden descomponer del cuadro sus elementos, que combinados, producen una relación rítmica. Yo en mi obra utilizo muy pocos módulos, durante años he hecho cuadros con el mismo módulo, lo único que los diferencia a unos de otros son las diferencias rítmicas. Cuando utilizo la palabra ritmo me refiero a esto, a la relación matemática existente entre los distintos elementos básicos del cuadro.

\section{¿Y el movimiento?}

- En mis cuadros no hay movimiento real, hay un movimiento representado, porque debido a la manera en que las distintas partes del cuadro se relacionan entre sí por esas relaciones rítmicas que poseen sus elementos básicos, el resultado final del cuadro invita a la visión a visualizar eso de una determinada manera, es decir, que el ritmo es la base del orden en mi obra, pero los conjuntos rítmicos que componen la totalidad de la obra crean unas trayectorias que tiran del ojo, te hacen recorrer el cuadro de una manera determinada; a este recorrido que sale, que es consecuencia de la composición de los elementos del cuadro, es a to que me refiero con el término movimiento.

\section{¿Y el espacio?}

- El espacio en mi obra no existe, o no existe o todo es espacio. Lo que desaparece en mi obra es la dialéctica forma-espacio, en mi obra todo es forma o todo es espacio, es decir, cada módulo se divide en dos partes, una negra y otra blanca, esto no quiere decir que lo blanco sea el espacio y lo negro la forma, no, mi obra tiene forma y antiforma, o espacio y antiespacio. Es decir, que no existe relación entre dos elementos antagónicos o complementarios, es lo mismo, lo blanco es forma y lo negro es forma, lo blanco es espacio y lo negro es espacio. Lo que estoy queriendo decir con esto en mi obra es algo que la naturaleza lo ha hecho de otra manera, la naturaleza tampoco divide al mundo, o al universo, en materia y espacio, sino en un sentido profundo de la última física todo es espacio; la materia no es más que espacio ordenado, diferencia de vibraciones, la diferencia de velocidad del movimiento con la energía del espacio es lo que hace las diferencias materiales y la diferencia entre espacio y materia. Al no ser físico no puedo explicar esto muy bien, esto es más bien un poco de intuición, es decir, los objetos materiales en realidad no existen, no existe la materia, todo es energía, las diferencias de vibraciones de estas energías conforman la materia. 


Q: Vurto Inmaculada España Cordero

En su obra modular se habla de criterio de selección intuitivo y privativo, ¿tiene esto algo que ver con la selección subjetiva?

- Sí, la selección es subjetiva, es intuitiva pero subjetiva. Yo utilizo muchos elementos formales, muchos elementos de orden matemático, de orden geométrico en mi pintura, pero no los utilizo de una manera voluntaria, pensada o predeterminada, yo dejo que me salga del interior lo que estoy haciendo, y luego elijo sin saber por qué me gusta. Una combinación modular que yo hago en la pantalla del ordenador: si al terminarla no me gusta, voy cambiando partes de esa composición, el cambio a lo mejor se produce simplemente girando uno de estos módulos, como los módulos son cuadrados en una composición cuadriculada puedes girar una cuadrícula con el módulo que lleva dentro o puedes girar medio cuadro o el cuadro entero. Lo que quiero decir con esto es que cuando estoy inmerso en un proceso por ejemplo de mejorar una composición que he hecho en la pantalla del ordenador y no me acaba de gustar, pero que pienso que cambiando una parte me puede gustar más, la guía para cambiar o no cambiar es simplemente la vista, el hecho de considerar si me gusta o no me gusta, no me rijo por leyes. Cuando llego por fin a la conclusión de que toda la composición me gusta, la adopto sin saber por qué, y la paso al lienzo. Todas las ideas que yo he expresado después de módulos, de ritmos, de movimientos y de elecciones, etc. han sido el resultado de meditaciones posteriores a la obra, estas ideas han surgido de la observación a la obra hecha.

O sea que su obra es subjetiva aunque tome elementos totalmente objetivos.

- Exactamente, lo has dicho muy bien, muy sucintamente y muy claramente.

En este punto, en cuanto a obra subjetiva, le aleja de gran parte de lo que han hecho y han dicho muchos artistas de la vanguardia, porque el carácter subjetivo de una obra es algo que se intenta eliminar de una obra de arte si se quiere que sea autónoma.

- Sí. Lo que ocurre en la mayoría de la obra de arte geométrica es que no tiene contenido, únicamente se preocupan del aspecto formal de la obra. Sin embargo a mí me interesa mucho el contenido, tanto es así que aunque sea una obra hecha con elementos muy objetivos como tú has dicho, yo busco, no tanto una obra expresionista, pero sí una pintura con algún contenido de tipo expresivo.

¿Cual es la situación de su obra modular en los últimos diez años?

- Desde el año ochenta y cuatro estoy utilizando los mismos módulos.

¿Qué piensa del minimal y de la abstracción postpictórica? 
- A mi el minimal me interesa muchísimo, de hecho mi obra es bastante minimal. Por lo que respecta a la abstracción postipictórica no sabría qué decirte, ahora no leo muchas revistas de arte, de joven sí, pero ahora mi obra se nutre de sí misma y continúa evolucionando. A mí las instalaciones no me gustan nada y pienso que es una moda porque el arte está cambiando continuamente y produciendo movimientos que fenecen por sí mismos, hay otros movimientos que no, hay otros que permanecen aunque desaparecen por un tiempo y reaparecen después.

Hablemos ahora del Centro de Cálculo de la Universidad de Madrid. Antes de que usted participara en los seminarios del Centro de Cálculo ya se estaban haciendo algunos trabajos de cierto valor artístico con el ordenador ¿Sabia de la existencia de estos trabajos? ¿ Y de considerar el ordenador como un instrumento de ayuda? Me refiero a que si tenia noticias de todo esto antes de participar en el CCUM.

- No conocía lo que se estaba haciendo con ordenador fuera de España porque no pertenecía todavía al campo del arte. Los ordenadores en aquellos tiempos eran unos mamotretos enormes, por ejemplo el Centro de Cálculo era un edificio grande y todo el edificio estaba hecho para contener un ordenador, sólo uno. El ordenador por entonces estaba constituido por una serie de consolas y de elementos todos ellos de gran tamaño, o sea, no existían los ordenadores personales, no había la posibilidad de hacer una investigación de arte con ordenador en tu estudio. Lo que ocurría es que empresas o compañías grandes, como la compañía Bell de Estados Unidos, o compañías de ordenadores que pertenecían al ejército, es decir, empresas de mucha envergadura que entre sus empleados había alguno que tenía alguna inclinación artística entre comillas, entonces jugaban con el ordenador haciendo experimentos y viendo qué era lo que se podía hacer plásticamente con el ordenador, pero no había artistas, hasta entonces los artistas no se habian incorporado al movimiento que después se llamó Computer Art porque no había la posibilidad de tener un ordenador en casa. A modo de curiosidad, más que de movimiento artístico, vi unas formas gráficas realizadas con ordenador, de hecho se llamaban gráficos de ordenador, concretamente en una revista vi uno de esos experimentos, no se llamaba arte de ordenador, se llamaba gráfico de ordenador, como he dicho antes. Yo llegué al ordenador por un proceso al que me impulsaba mi propia obra, pues yo trabajaba con los mismos módulos durante años, lo que diferenciaba una obra de otra era la forma de combinarlos; a mí me intrigaba el hecho de que entre dos cuadros del mismo tamaño, con el mismo número de cuadrículas, con el mismo número de módulos y siendo estos módulos los mismos entre los dos cuadros, por qué me gustaba uno más que otro, o sea, el tema es el que hablábamos antes, el de la intuición, el de lo subjetivo. Yo quería saber por qué uno me interesaba y otro no, entonces yo pensaba, si estos dos cuadros están hechos con los mismos ingredientes, por qué son distintos, qué diferenciaba uno de otro. De hecho esa era ya la larva del ordenador, porque había que analizar esos dos cuadros para ver qué es lo que los diferenciaba, entonces yo sabía que esto era algo que un ordenador podía hacer. Ya había leído algo por casualidad sobre cibernética, en concreto el libro 
de Norbert Wiener Cibernética y Sociedad, este libro me causó un fuerte impacto, me hizo buscar otro libro sobre lo cibernético. Por entonces ya sabía perfectamente cómo trabajaban los ordenadores y lo que podia hacer un ordenador.

O sea, antes de su participación en el CCUM ya pensaba que el ordenador le podia ayudar ¿no?

- De hecho, antes de participar en el Centro de Cálculo, yo ya estaba actuando como un ordenador, mis cuadros estaban siendo pintados como un ordenador. Al ordenador le puedo dar los elementos básicos, los módulos, y decirle que me los combine dándole una serie de normas que deben cumplirse y otras que no deben cumplirse. Eso mismo estaba haciendo yo con mis cuadros de una manera muy lenta, pero la semilla de lo que después hice con el ordenador ya lo estaba haciendo manualmente. Llevaba desde el año 64 trabajando con el mismo módulo que tenía partes rectas y partes curvas hasta que entré en contacto con el Centro de Cálculo, y cuando entro en contacto con el Centro de Cálculo ya tenía muy claras las ideas sobre el papel que debía tener el ordenador en mi obra. Asistí a un curso sobre ordenadores en el año 68, antes que nada debo decir que durante el curso se creó un seminario para el estudio del arte y los ordenadores, y en las intervenciones del seminario yo me refería mucho al papel que el ordenador tenía en mi propio arte. Este curso no era un curso para pintores, de hecho no llegaron a pensar que se pudiese crear un seminario para el estudio del arte y el ordenador. Los asistentes a los cursos debían ser licenciados de carreras, ya que la finalidad del Centro de Cálculo era divulgar la idea entre los profesionales del papel del ordenador en sus distintas profesiones o puestos oficiales. A manera de curiosidad me pidieron que diese unas conferencias a los asistentes al curso sobre mi caso concreto, es decir, sobre el arte y el ordenador, entonces hablé sobre todas esas cosas que yo ya las pensaba gracias a los libros que había leído de informática. Tengo que aclarar que estos cursos eran para posgraduados, había que ser licenciado en una carrera universitaria para poder asistir a los cursos, por lo que los pintores teníamos o tenían el camino cerrado. Pero yo soy licenciado en Derecho, esto me valió para que me admitieran en este curso, de hecho me concedieron una beca, hice una memoria hablando de lo que pensaba y de lo que podía hacerse con el ordenador, pero lo que me abrió las puertas fue ser licenciado en Derecho. Después, cuando ya se creó el seminario sobre Formas Plásticas y ordenador y arte, ya se eliminó el requisito de licenciado para poder darle entrada a los artistas, porque no todos los artistas son licenciados en una carrera universitaria. Pero cuando yo asistí me tuve que valer del título de Derecho, que yo creía que nunca me iba a servir para nada, y me valió para que me admitieran. O sea, que yo llegué al ordenador sin saber, pero habiendo visto representaciones gráficas, y llegué para que el ordenador me simplificase el trabajo, como una herramienta de ayuda, pero sobre todo con una base combinatoria. La obra gráfica anterior de ordenador no había tocado la combinatoria, ní siquiera las formas geométricas, a menos que llamemos forma geométrica a la representación de una ecuación matemática. 
Entonces, ¿usted fue el primero?

- Fui el tercer artista, o sea, la tercera persona con unos precedentes artísticos que usó el ordenador a nivel mundial, y el primer europeo. Porque entre las obras que se habían hecho con anterioridad había un par de personalidades que habian tenido una formación artística, aunque sus profesiones eran las de informático. Es decir, ya había habido dos personas, que habían hecho de alguna manera u otra una obra gráfica, eran programadores, pero habian tenido una formación artistica anterior. Solamente dos habían experimentado antes artísticamente con ordenador. En una conferencia que di en la Facultad de Ciencias de la Información, divido la evolución del Computer Art en tres etapas, en la primera etapa a la que yo llamo "de los matemáticos", ya que éstos eran los únicos que tenían acceso a los ordenadores, es donde están estos dos que tienen algunos precedentes artísticos, alguna formación artística, aunque no hayan liegado a ser unos artistas convencidos, pero que han experimentado de alguna manera. Artistas profesionales, los primeros que se incorporan al Computer Art, son los del Centro de Cálculo de la Universidad de Madrid.

O sea, hay que destacar la precocidad del CCUM en un país como España, inmerso aún en una dictadura, con años de retraso si se compara con Alemania por ejemplo, que sea España la primera que investigue en este campo es un mérito ¿no?

- Yo creo que sí. De hecho en este artículo me pregunto si fuimos o no fuimos los primeros. Si los autores de la etapa que yo llamo "de los matemáticos" hicieron, aún sin proponérselo, algo que es arte, entonces nosotros no fuimos los primeros. Pero si lo que hicieron los matemáticos no es arte, es simplemente jugar con el ordenador, entonces somos los primeros del mundo. Desde luego, profesionalmente, con experiencia artística, exposiciones y un cierto nombre en el mundo artístico, el grupo del Centro de Cálculo fue el primero del mundo que se valió del ordenador. De hecho incluso hasta nos adelantamos a la aparición de los ordenadores personales, porque nosotros sólo trabajamos con el gran ordenador del centro de Cálculo, sin embargo la popularización del Computer Art y el acceso de los artistas al ordenador se produce cuando aparecen en el mercado los ordenadores personales, que ya están al alcance del bolsillo de individuos aislados y su tamaño es para tenerlo en casa.

Pero hubo un período, concretamente en la década de los setenta, en el que usted dejó de utilizar el ordenador, ¿no es asi?

- Sí, hasta la aparición de los ordenadores personales, sólo utilizamos el ordenador del Centro de Cálculo.

O sea, en los años setenta dejó de utilizar el ordenador porque usted dejó de asistir a los seminarios del CCUM y no existia la posibilidad aún de tener un ordenador personal. 
- El trabajo en el Centro de Cálculo era muy engorroso. El Centro de Cálculo no había sido creado para nosotros, estaba al servicio de la Universidad y de los organismos oficiales, y como era sólo un ordenador el que había, cuando te llegaba el turno ya estabas trabajando en otra cosa. La lentitud, las dificultades y por manipulaciones que había de gente que se valía de contactos para conseguir que su trabajo pasara por la máquina antes que otros, por muchas razones, pero sobre todo por lo engorroso que era pensar algo, pues lo primero que tenías que hacer era el programa, y al no tener idea nosotros de programar el Centro pedía a uno de sus becarios que ayudase a un artista o a un grupo de artistas. Cuando conseguíamos que algún becario pudiera ayudarnos, ellos hacían el esquema del programa, el organigrama, o incluso hacían el programa completo sobre papel, pero para que la máquina se pusiese en funcionamiento había que darle a la máquína ese programa con fichas perforadas, es decir, que para hacer un programa de ordenador, y al funcionar aquellos ordenadores con fichas perforadas, a lo mejor había que darle una gran cantidad de fichas perforadas, pues cada ficha sólo contiene una pequeña cantidad de información, entonces una vez que el programador hace el programa nosotros teniamos que hacer todas las fichas. $Y$ como los estatutos del Centro eran que tenía trabajar al servicio de la Universidad y al servicio del ministerio tal o el ministerio cual, cuando llegaba tu turno y el ordenador tenía que procesar la información gráfica del programa que le habías dado, entonces ya estabas pensando en otra cosa.

Esta lentitud de la que me habla, los contactos de favor, las rencillas, ¿le hicieron abandonar el Centro?

-. Más que rencillas, había gente que se valía de la amistad, de los contactos con Fulano o Mengano, que era la persona que manejaba el ordenador en aquel momento, para conseguir que sus trabajos pasasen por la máquina antes que otros, o gente que utilizaba su cargo dentro del Centro de Cálculo como un elemento de poder; estas personas enturbiaron mucho la cosa, porque tenían favoritismos; o sea, que habia una serie de elementos extra-ordenador y extra-artísticos que creaban dificultades. A todo elio se une que yo vivía en Málaga y el seminario estaba en Madrid, eso significaba ir casi una vez a la semana y estar varios días allí por lo que estaba continuamente en el camino. Esto era muy pesado, además cuando volvía con obra gráfica producida por el ordenador esto suponía traer unos grandes tacos de impresos que luego tenía que revisar uno por uno, y a lo mejor de todo ello rechazaba el $99 \%$ valiéndome de mi criterio subjetivo, es decir, diciendo este vale, este no vale, este me gusta o este no me gusta. Encontrar un impreso que me gustase significaba el tener que haber ido a Madrid, estar tres días, en fin, era una manera de trabajar que me agotó y entonces dije: pues se acabó el ordenador, yo sigo haciéndolo a mi manera, manual, lenta, hasta que aparecieron los ordenadores personales hacia el 79 u 80 . 
De todas formas el Centro de Cálculo seria una experiencia positiva para usted ¿no?

- Para mí fue muy positiva, yo creo que tuvo una gran importancia artística a nivel nacional, lo que ocurre es que al mundo de las galerías, de las revistas de arte y todo eso no les interesó demasiado. Ahora parece que hay un revival, ahora se están preparando dos exposiciones sobre los trabajos del Centro de Cálculo, una va a ser en la zona de Levante, que posiblemente pase de universidad en universidad; y en Sevilla están organizando otra exposición que también va a estar centrada en los trabajos del Centro de Cálculo.

¿Ha aprendido a programar? En su tesis sobre los origenes del arte cibernético en España, Enrique Castaños Alés dice que usted no aprendió a programar en el tiempo que estuvo en el CCUM, en la actualidad si ¿no es cierto?

- Cuando ya tuve el ordenador personal empecé a aprender programar.

O sea, que ya no necesita de la ayuda de ningún programador ni de ningún informático para nada.

- No, ya ni siquiera necesito programar más nada porque tengo hecha una serie de programas que cubren mis necesidades. Hace tiempo tuve un interés muy grande por el fenómeno internet, luego llegué a la conclusión de que no me aportaba nada, o sea para mi trabajo los programas son suficientes, ya que a mí lo que me interesa es pintar. Tengo un hijo que es informático, porque se crió rodeado de ordenadores, el primer ordenador personal que yo tuve era un Spectrum, tenía más memoria y más capacidad de procesamiento que el ordenador gigante del Centro de Cálculo, entonces mi hijo se crió en casa primero con un Spectrum, luego con un Commodore, etc., o sea que fue aprendiendo por su propia cuenta, luego se empezó a interesar en las revistas de informática, luego estudió la carrera de informática y ahora trabaja como informático. Lo que te quiero decir es que fuimos los dos aprendiendo a programar simultáneamente, él más rápidamente que yo, porque los niños tienen más habilidad para esas cosas, para el mundo tecnificado de hoy en día, tanto es así que cuando yo estaba aprendiendo a programar a veces me encontraba con obstáculos que mi hijo me resolvía, se ponía conmigo frente al ordenador y nos poníamos a buscar, a rastrear por el programa hasta que dábamos con el problema, era él muchísimas veces el que resolvía el problema. Como te decía, juntos fuimos aprendiendo a programar y en un par de años o así, después de haber tenido el primer ordenador personal, yo ya programaba hacia principios de los ochenta.

¿Qué hubiese pasado con su obra modular de no haber recibido el impulso que la participación en los seminarios del CCUM supuso? ¿Hubiese abandonado su obra modular, hubiese evolucionado hacia otro aspecto o con el paso del tiempo hubiese empleado el ordenador? Bueno ya me dijo anteriormente que usted pensaba que su obra estaba hecha para ordenador, ya antes de participar en el CCUM pensaba esto, 


Q: Vinmaculada España Cordero

o sea, que si el CCUM no le hubiese brindado esta oportunidad hubiese pasado el tiempo hasta la espera de que alguien le hubiese brindado esta oportunidad ¿no?

- No, creo que mi obra hubiese evolucionado más lentamente, porque por ejemplo la asistencia al curso de ordenadores en el Centro de Cálculo produjo el que yo pasase de utilizar un sólo módulo a cuatro, no porque yo lo pensase, sino que este hecho se produjo espontáneamente, de pronto me encontré experimentando con otras formas, buscando sin saberlo otros módulos, hasta llegar a un conjunto de cuatro. Quizás esto no hubiese ocurrido si no hubiese ido al Centro de Cáículo, o hubiese ocurrido diez años después, para mí hubiese sido más lenta la evolución, aunque yo creo que el resultado hubiese sido el mismo, porque con ordenador o sin él mi obra se rige por unas normas fijas, sin ordenador la evolución hubiese sido la misma, pero más lenta.

Cuando descubrió los tres módulos más tras haber estado trabajando durante casi cuatro años con el mismo módulo, usted dijo en alguna ocasión que estos módulos operaban básicamente igual que el primero. El descubrimiento o el aumento del número de módulos con el paso de los años isiguen confirmando esta idea? ¿Trabajan con las mismas leyes?

- Sí. O sea, es pura combinatoria con dos o tres modalidades de operación junto con la inversión de color.

Por otra parte el aumento del número de módulos se debe: al perfeccionamiento de los programas de ordenador, a una evolución necesaria de su obra, ¿o a ambas cosas?

- Yo creo que mí evolución positiva va siempre por delante del ordenador.

Entonces esto no tiene nada que ver con los programas.

- No, lo que pasa que el programa nuevo me agiliza el proceso, a raíz de producirse un cambio los cambios posteriores vienen más rápidos con la ayuda del ordenador.

Parece evidente que el descubrimiento de la pintura modular por su parte de manera casi inconsciente era lo que buscaba, ya que son casi cuarenta años trabajando con la pintura modular, cosa que si se compara con otras etapas anteriores de su obra que son relativamente cortas, y hasta efimeras, resulta evidente.

- Yo creo que sí, porque a partir de la aparición de un determinado módulo ya mi evolución se hace mucho más lenta, se desarrolla dentro de los mismos carriles; hasta entonces había ido picoteando en todo lo que se habia hecho en la historia de la pintura, pasando a lo mejor por un período con un par de cuadros, y enseguida 
pasaba a otra cosa. O sea, era una evolución muy rápida, yo me decía: esto lo tengo que probar, cuando lo probaba y comprobaba que no me llenaba pasaba a otra cosa. Hasta que llegué al módulo y a la pintura en blanco y negro y entonces todo se sedimenta, y es mucho más lento.

Es como si alcanzase la esencia de la pintura para usted ¿no?

- Bueno lo que ya estaba dentro de mí, porque yo recuerdo que en Marruecos, no sólo lo gráfico, lo visual, sino también la fascinación que me producía la música marroquí, esta música es muy repetitiva, muy modular, yo recuerdo como por las noches en la cama ponía la radio y cogía las emisoras marroquíes, a veces me dormía casi al amanecer, ya se me ha pasado ese interés, pero lo viví con gran intensidad, produciéndome emociones fuertes esa música.

\section{Como vemos la relación de la música con su obra modular es muy fuerte ¿no?}

- Sí. En Marruecos de todo lo modular, aparte de la arquitectura y la decoración, lo más modular es la música, lo que más impacto me produjo a mí fue la música marroquí, sin embargo lo modular no aparece en mi obra hasta casi diez años después, pero yo creo que la semilla fue entonces.

¿Tienen algún significado simbólico el blanco y el negro, el cuadrado y el círculo en su obra? Porque normalmente estas figuras geométricas y estos colores a lo largo de la historia han tenido una significación simbólica, ¿en su obra la tienen?

- Sí, la tienen. Yo creo que en mi obra lo más importante es la dualidad, mi obra es dual en todos sus aspectos, si en una parte del cuadro hago una cosa, en la parte contraria hago exactamente lo mismo, pero girado, no pongo cualquier cosa. Todo tiene su contrapartida, por otro lado los números que a mí me interesan y que suelo emplear más son el dos, el cuatro..., son los pares, los impares casi no me interesan, en cambio los números pares tienen un atractivo especial para mí. Respecto al blanco y al negro los utilizo porque son los dos colores que más claramente dicen que son opuestos.

O sea, los que confirman ese lenguaje dual que existe en su obra.

- Efectivamente. En mi obra la dualidad no solamente consiste en la utilización de las parejas de cosas, sino también en que esas parejas son opuestas, contrarias. Yo no soy filósofo ni he estudiado filosofía, pero la dualidad para los antiguos pensadores era muy importante; por ejemplo los pitagóricos pensaban que la esencia de las cosas es el número y el juego de los contrarios, para toda la escuela de pensamiento de Pitágoras el juego de los contrarios lo consideraban muy importante, así como en la música y en la armonía. Otro tipo de pensamiento, el de los templarios, los cuales tenían como bandera un rectángulo dividido en una mitad 
blanca y la otra negra; los masones cuando tenían una reunión lo hacían en una habitación llena de símbolos, uno de los símbolos es que parte del pavimento estaba repleto de losetas blancas y de losetas negras.

En definitiva el carácter simbólico de su obra radica en su dualidad.

- La dualidad yo la relaciono con el ordenador a través de la informática, la unidad elemental del lenguaje informático, el bit, no es una cosa, son dos cosas, el uno y el cero juntos, es un sistema binario, algo así pasa con mi pintura que no tiene forma y espacio, o los dos son forma, o los dos son espacio, es como el bit. Esto es muy importante en mi pintura, y aunque pueda sonar un poco pedante 0 un poco pretencioso yo creo que esto es importante en mi pintura porque el universo es así; en sentido muy estricto mi pintura seria una pintura muy realista, lo que pasa es que por pintura realista entendemos la pintura que representa imágenes conocidas por nosotros y que nosotros creemos que son las cosas que existen. Por ejemplo una mesa o una silla están compuestas de moléculas y de átomos, estas moléculas y estos átomos son a lo mejor el equivalente al bit de la informática, o a la forma y antiforma de mi pintura.

Me acabo de acordar de una cosa en relación con su pintura geométrica; Malevich cuando pintó su Cuadrado negro sobre fondo blanco, dijo que esta era la máxima expresión de la pintura, o sea, pintura pura pues el cuadrado era una creación del hombre, que no se encontraba en la naturaleza y por lo tanto no copiaba nada, ¿ha oido esto alguna vez?

- Yo no conocía este pensamiento de Malevich, pero efectivamente el cuadrado ya no tiene relación ninguna con lo visual, con el mundo visual, es una creación pura.

Entonces en su obra que el cuadrado es un parte fundamental, se relaciona con la naturaleza más que nada por el funcionamiento, por parecerse a un organismo que va creciendo y que está formado por varios elementos ino?

- En mi obra sí.

Como movimiento de vanguardia radical para Malevich y compañia no tenia ningún interés copiar una cosa o a un grupo de gente haciendo algo determinado, para ellos esto no era arte.

- Para Malevich y Mondrian no, pero ha habido otros pintores geométricos, como por ejemplo el matrimonio Delaunay, que sí hacen una obra geométrica que tiene relación con el mundo visual. Mondrian se limita a los espacios, realiza unos trazos y los rellena de un color uniforme, lo que no utiliza apenas es el cuadrado; Malevich en cambio apenas utiliza el color pero sí el cuadrado, figura que repite y repite. Pero yo creo que mis padres artísticos son éstos. 
Este es un tema que da para mucho, lees una cosa, luego otra completamente distinta, y cuando empiezas a leer sobre las vanguardias e intentas buscar la relación entre la vanguardia histórica y su obra te encuentras con que hay muchos puntos en común aunque no todos resultan serlo.

- Yo creo que mi obra tiene mucha más relación con la física que con otros movimientos pictóricos, porque la física también dice lo mismo que Malevich, o sea, que las cosas no existen, son ilusiones que nosotros nos creamos. Eso es lo que vino a decir Malevich, o sea, vamos a partir de algo, y ese algo es una representación intelectual, una representación artística, el cuadrado; luego sobre distintos métodos, como en el caso de mi obra, por la modularidad, por los giros o por los cambios de color, se crea un conjunto mediante un proceso de subconjuntos, que luego a su vez crean macroconjuntos, todo esto con una base como decía Malevich inexistente.

Que no tiene referencia externa alguna ¿no?

- Claro.

¿Qué opina sobre lo que dice Enrique Castaños Alés en su articulo "Razón, Intuición y Símbolo" de considerarle más como un destacado representante de la abstracción pura, más que un artista cibernético puro u ortodoxo? Para ello expone que tanto la técnica como el soporte en su pintura son tradicionales, que su pintura modular ya existia antes de que usted entrase en el CCUM o el hecho de que usted compartió muchos problemas, así como la solución a estos problemas con los artistas de la vieja vanguardia, es decir con el Constructivismo, con el Suprematismo y con el Neoplasticismo.

- El conjunto de los pintores de ordenador, los que yo llamo "los matemáticos", no tenían una formación o un interés primordial artístico, sino más bien cibernético. Yo creo que con esto Enrique Castaños Alés intenta resaltar el aspecto artístico de mi personalidad, para no dejar que el aspecto cibernético se coma al artístico, quiso resaltar que yo hacía este tipo de pintura años antes de entrar en contacto con el ordenador.

Por lo tanto usted es un artista abstracto puro, más que un artista cibernético puro.

- Sí.

O sea, la cibernética juega un papel importante en su obra actual, pero no es el fundamento, pues hay muchos puntos que usted comparte con la vanguardia histórica, aún inconscientemente.

- Yo creo que sí, que si los analizas los encuentras. De todas formas yo le agradezco mucho a Enrique Castaños Alés el siguiente hecho: ahora parece que hay 
un revival del arte del Centro de Cálculo, pero hace unos años se consideraba que el Centro de Cálculo era una cosa que ya estaba muerta y enterrada, y quiso dar a entender que si esto era algo que ya estaba muerto y enterrado, a Barbadillo no había que incluirlo porque ya hacía pintura modular antes de esto. Era como una flor que él me echó.

En mi trabajo hay un capítulo en el que intento buscar puntos de unión a través de todo lo que usted ha escrito y hecho con los escritos de Kandinsky, Malevich y Mondrian, sobre todo, aunque algunas ideas estén muy cogidas por los pelos, pero yo también creo que existen muchos puntos de unión, incluso más de lo que usted se piensa.

- Sí. Yo no soy muy aficionado a este tipo de lectura porque temo caer en lo tópico. Pero sí, Kandinsky de hecho habla del blanco y el negro.

Él también habla del carácter subjetivo, interior, que debe tener una obra. Como verá existe una gran cantidad de puntos en común, con el Neoplasticismo también, cuando habla de cultura universal por ejemplo. Entonces, ¿cómo ve usted esa relación que hacemos varios historiadores del arte de su obra con la vanguardia histórica?

- Yo creo que hay una relación, de hecho mis verdaderos padres artísticos son Malevich, Kandinsky y Mondrian.

\section{¿Y Vasarely?}

- Vasarely menos, es muy abstracto, vivió en París y estuvo afectado por los franceses, los franceses son muy cartesianos, analíticos, tienden a diseccionar, y Vasarely hace una trama cuadriculada, en cada cuadrado va metiendo un elemento, no consigue dar una unidad artística a sus cuadros, entonces recurre a la ilusión del relieve para que de unidad al cuadro. Vasarely divide, divide y divide, y luego se encuentra con que esas divisiones no tienen una unidad estética, entonces para dar iłusión de que si la tiene hace como si estuviese abombado, y todo lo que está dentro de ese abombamiento, forma parte del abombamiento, valga la redundancia, y así piensa que ha conseguido la unidad. Ese desmigajamiento del cuadro es muy cartesiano, muy analítico y muy francés.

Pero su obra es también muy analitica ¿no?

- Sí, es muy analítica, pero el elemento oriental a través de la música marroquí es muy importante en mi obra; en Vasarely no es así, Vasarely no tiene ritmo, porque es la misma forma que se repite, pero esta misma forma no se une a la forma vecina, o sea, presenta formas unas al lado de la otra, este cartesianismo extremo es muy francés, también utiliza muchos colores bonitos, cosa que también es muy francesa. 
Pero también es posible que Vasarely me influenciara de alguna forma, con la cuadriculación del cuadro, el partir de una malla cuadriculada, lo que ocurre que donde Vasarely mete en una cuadrícula un objeto y lo deja puesto, yo meto un objeto que está tratando de fundirse con el objeto de la cuadrícula adyacente, y éste a su vez con el de otra cuadrícula adyacente, y a través de estas sucesiones de los módulos de unos con otros trato de crear movimiento rítmico. Esto no le pasa a Vasarely, Vasarely no tiene ritmo, o si tiene ritmo es de uno por uno, es decir, coge un campo que divide en porciones idénticas, en cada una de estas porciones pone unas formas cerradas sobre si mismas que no tienen nada que ver con las restantes. Pero puede ser un precedente, lo que pasa es que yo no puedo dejar estas partículas quietas, sino que tengo que tratar que dialoguen con las que le rodean, para a través de ellas hacer una melodía, es decir, trato de imprimirles el movimiento, el ritmo, que es la totalidad del cuadro. Lo que trato de decir es que el contenido, la parte inconsciente y el elemento oriental en mi obra son tan importantes como la geometría y la composición.

Cuando he estudiado la relación de su obra con la vanguardia histórica hay un punto en el que se relaciona bastante con el Neoplasticismo y con Mondrian, a través de esa idea de devolver el arte a la praxis vital de la vida. ¿Usted qué entiende por devolver el arte a la praxis vital?

- Yo creo que con esto quiero decir que mi arte es muy realista, no es una elucubración relacionarlo con la naturaleza, porque mi arte es una representación de la naturaleza, lo que pasa es que es una representación de la naturaleza a un nivel muy alejado de la naturaleza visible.

¿Y eso de que el arte es un instrumento que puede ayudar a cambiar el mundo, el hombre y la sociedad?

- Yo creo que el arte cambia la sensibilidad de las personas, por ejemplo con la música clásica tu sensibilidad cambia. Tu sensibilidad está en el subconsciente, y yo he llegado a la conclusión de lo que haces racionalmente es la consecuencia de un proceso previo que ha tenido lugar en el subconsciente y que ha tardado algún tiempo en hacer la elaboración para después aflorar en la mente; si cambia la sensibilidad está cambiando la mente, y si cambia la mente cambia el mundo.

La sensibilidad desempeña un papel importante para usted ¿no?

- Sí, para mí es un elemento básico del arte.

En este punto usted se acerca bastante a Malevich, Malevich decia que el arte era la representación máxima de la sensibilidad en su "Manifiesto suprematista".

- Sí, entonces sí, aunque yo no lo he leído. 
Hay muchos puntos de unión, aunque parezca que no, con la vanguardia histórica. Con Kandinsky por ejemplo se acerca bastante a esa afinidad con la música, pues éste consideraba la música como el arte más puro que existe, que no tiene referencia alguna con nada exterior, entonces él en su libro De lo espiritual en el arte nos viene a decir algo asi cómo que las demás artes deben acercarse lo más que pueda a la música con el fin de ser más pura, o más autónoma posible, porque la música no remite a nada, sino a si misma. Y si hablamos de su obra modular parece que ésta se basa mucho en el lenguaje musical, y como me ha dicho antes, sobre todo, en la música marroquí.

- La crítica en general no suele ver eso porque suele considerar como musical los colores, cuando hacen la crítica a la obra de un artista la consideran musical respecto al color. En mi obra to musical es lo modular, el ritmo, no el color.

Entonces su relación con la vanguardia histórica es más inconsciente, por su parte, que consciente ¿no?

- Sí, es inconsciente. Tú has estado haciendo referencia a textos de ellos que yo nos lo conocía.

¿Usted es consciente de que ha creado escuela? ¿Conoce algún artista o grupo de artistas que hayan seguido su obra o se hayan basado en ella?

- La primera persona que hizo pintura modular en España fui yo, por lo tanto a todos los artistas que hacen una obra modular actualmente mi obra les puede servir de inspiración a este tipo de pintura.

Sólo voy a hacer una apreciación a un aspecto de la evolución de su obra que puede resultar un tanto discutido, el paso de una pintura de materia a una pintura abstractogeométrica supone un paso muy grande, pero yo defiendo que en medio hay una etapa abstracto-estructurada que tiene de las dos partes, por un lado esta etapa abstracto-estructurada es pintura de materia en cuanto a la técnica, por otro lado ya existe una estructuración, un lenguaje más o menos binario que va sentando las bases de lo que posteriormente iba a hacer, por lo tanto se puede considerar esta etapa abstracto-estructurada como el puente entre lo que hizo anteriormente y lo que hará más tarde.

- Sí, exactamente. Primero el cuadro fue una superficie entera texturada, luego empezaron a aparecer ejes, verticales y horizontales, que van dividiendo esa superficie en porciones, luego esas porciones cada vez se iban pareciendo más unas a otras.

- El periodo abstracto-estructurado de su obra está ya entre dos aguas, repito, por un lado está la pintura de materia que es más que nada por la técnica que sigue, por 
otro lado ya se ve claramente un lenguaje binario, aunque el blanco y el negro no hayan tenido aún su aparición, pero el diferenciar dos zonas claramente supone algo ¿No es asi?

- Es así, es un periodo donde unas formas son salientes y otras entrantes, ese es el camino para una pintura de materia, después cada uno de los trocitos se fueron igualando, hasta que fueron idénticos, cuadrados.

Después llega un momento en el que iguala la textura y empieza a trabajar en blanco y negro. Eso es lo que yo trato de explicar, pero alguien me puede decir que el paso de una pintura informalista, como es su pintura de materia, a una obra abstractogeométrica es un giro de 180 grados, es un salto grandísimo y no hay sensación de continuidad.

- Lo que ocurre es que esto se puede ver desde dos grupos distintos, por un lado el de los pintores de materia y por otro lado el de los pintores abstracto-geométricos, en dos fenómenos artísticos distintos, como dos cosas separadas.

Cuando el informalismo llegó a su fin, fin entre comillas pues aún hoy se sigue haciendo este tipo de pintura, lo que se queria era renovar el ambiente artístico y entre otras cosas surge una tendencia abstracto-geométrica. Pero claro, usted desembocó en la abstracción-geométrica inconscientemente, sin pensar voy a hacer esto porque es lo que se está empezando a hacer.

- De hecho cuando me salió el primer cuadro pintado en blanco y negro ya sin textura me quedé sorprendido, y pensando que poca cosa, esto no es un cuadro, debe tener algo más, falta algo, pues esto es un cuadro bianco con algunas manchas negras. Esto me produjo un desconcierto. Luego empecé a jugar con relieves en cartulina y en madera, haciendo lo mismo que hacía en blanco y negro, empecé a ver la relación entre los relieves en dos planos y la pintura en dos colores, lo que no me pasaba todavía por la cabeza era la idea del dualismo y las implicaciones de tipo filosófico.

Pero el dualismo ya estaba germinando en su obra abstracto-estructurada mucho antes de que se diese cuenta ino?

- Sí. De todas formas yo creo que hay gente que puede ver mi obra como clasificaciones, no ven el flujo, el fluir de las cosas. Entonces la gente en vez de ver el flujo ven congelaciones de fases del flujo. Este es el problema que yo le veo a la academia, por eso me interesa más Kandinsky que Vasarely, porque Vasarely divide y congela las porciones, esa idea del ritmo y el movimiento la destruye. Hay que representar la vida como un flujo. Por último te voy a decir una cosa, yo creo que lo orientales están más interesados por el espíritu que por la materia, buscan la representación del espíritu mediante la representación del flujo en la música, etc. Los 
occidentales tratan de representar la realidad mediante el análisis, la división, la cuadriculación. Mi obra no es que sea orientalizante, ni occidentalizante, es las dos cosas, porque me interesa mucho el flujo, de hecho en la realización de un cuadro me dejo llevar por el flujo de sentimientos interno, más que el análisis visual, pero al mismo tiempo parto de una cuadrícula y de unos elementos geométricos básicos, o sea, creo que es una sintesis entre oriente y occidente.

¿Cree usted que existe alguna relación entre su obra modular y las culturas primitivas $y$ antiguas?

- La cultura primitiva es figurativa, es una figuración muy esquemática. El hecho del esquematismo ya nos relaciona. 